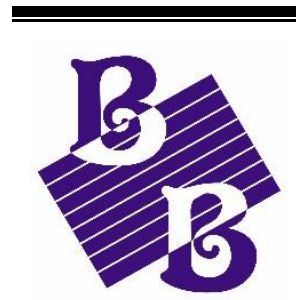

BioBacta
Journal of Bioscience and Applied Research

www.jbaar.org

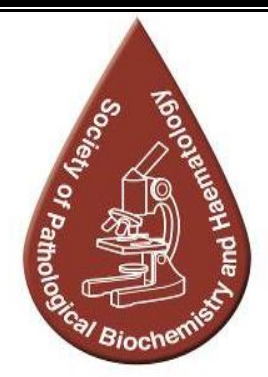

\title{
Serum cytokine profile during disease progression stages in male and female
} hepatitis $\mathrm{C}$ patients

\author{
Abdel-Rahman N. Zekri', Abeer M. Badr'², Shimaa Rabah², Maysa El Razky ${ }^{3}$, Somaya El Deeb² \\ ${ }^{1}$ Molecular Virology and Immunology Unit, Department of Cancer Biology, National Cancer Institute, Cairo University, \\ Cairo 11976, Egypt. \\ ${ }^{2}$ Zoology Department, Faculty of Science, Cairo University, Giza, 12613, Egypt. \\ ${ }^{3}$ Hepatology Department and Tropical Medicine, Faculty of Medicine, Cairo University, Cairo, 11441, Egypt. \\ * Corresponding author. E-mail address: abeerbadr@gmail.com
}

\section{Abstract}

DOI: 10.21608/jbaar.2019.147369

T helper (Th) cytokines play a key role in the immunological aspects of hepatitis $\mathrm{C}$ virus (HCV) pathogenesis. The pattern of Th1 (IL-2, interferon (IFN)- $\gamma$ ), Th2 (IL-10), and immunomodulatory cytokines (IL-12, IL-1 $\beta$, IFN- $\alpha$ and tumor necrosis factor- $\alpha$ receptor (TNF- $\alpha$ R2) balance participated in the outcome of host immune responses. The study aimed to investigate the serum levels of Th1/Th2 and immunomodulatory cytokines in $\mathrm{HCV}$ infected patients in both genders during various liver disease stages compared to healthy controls. Blood samples were collected from 16 healthy individuals and 77 patients at different disease stages including chronic, cirrhosis, and hepatocellular carcinoma (HCC). Serum cytokine levels were measured by ELISA. Levels of serum IL-12 and IL-10 were significantly higher in both genders in all groups than those in corresponding healthy subjects. Whereas, HCV infected female patients showed significantly lower levels of IL-2, IL-1 $\beta$, IFN$\alpha$ in chronic and cirrhosis stages than corresponding males. The serum level of IFN- $\gamma$ could be utilized as a biomarker for early detection of HCC. Finally, cytokine response variation in gender during various stages of the disease, implying that the subsequent activation and attenuated functional immune responses displayed differences in the balance of Th1 and immunomodulatory related cytokines between females and males upon infection.

Keywords: Cirrhosis, Cytokines, Gender, HCC, HCV, T helper cells. 


\section{Introduction}

The prevalence of hepatitis $\mathrm{C}$ virus (HCV) infection is nearly 170 million individuals throughout the world. Eighty percent of the infected subjects display chronic HCV. This chronic infection is associated with inflammatory liver injury and subsequent increase incidence of liver cirrhosis and hepatocellular carcinoma (HCC) (Lin et al., 2015).

Cytokines are small glycoproteins secreted by various immune cells and other types during natural and acquired immune responses, regulating some physiological, immunological, and pathological functions. They are the functional key players of host immune mechanisms during hepatitis $\mathrm{C}$ infection (Steinke and Borish, 2006). Activated CD4+ T cells can be differentiated into various subsets depending on their cytokine secretion profiles. The $\mathrm{T}$ helper type 1 (Th1) subset secretes interferon-gamma (IFN- $\gamma$ ), tumor necrosis factor-alpha (TNF- $\alpha)$, and IL-2, and participates in cell-mediated immune responses (Jordan et al., 2017). Type 2 (Th2) subset produces IL-4, 5, 13, and IL-10 that promotes humoral (Hurdayal et al., 2017) as well as allergic responses (Paul and Zhu, 2010). The balance of the Th1/Th2 cytokine axis was suggested to be an important factor in defining the rate of $\mathrm{HCV}$ persistent and HCVinduced liver injury (Zhang et al., 2014). The infection with virus $\mathrm{C}$ promotes cross interaction of innate and adaptive immune responses. Responses associated with $\mathrm{CD}+4$ and $\mathrm{CD}+8 \mathrm{~T}$ cells have participated in the clearance of $\mathrm{HCV}$ infection but ultimately failed to eliminate the virus infection initiating the destruction of hepatic cells.

The mechanism of chronic HCV pathogenesis is not fully identified, the role of cytokines is believed to be involved in both immune-regulation or immune impairment. $\mathrm{T}$ cell-related immunoregulatory cytokines maybe participated in the persistence of $\mathrm{HCV}$ infection leading to damage of the liver.
Chemokines helped in the recruitment of leukocytes and $\mathrm{T}$ cells to the sites of inflammation (Wald et al., 2007). This study aimed to evaluate Th1/Th2 cytokine profiles and the immunomodulatory cytokine levels in serum of HCV-positive patients in different stages of hepatitis liver disease compared to healthy control subjects. The influence of gender differences on the immune response of $\mathrm{HCV}$ infected patients was also assessed. To evaluate the relationship between expression levels of these cytokines and various markers of hepatitis liver disease.

\section{Materials and Methods}

\section{Study population}

Peripheral blood samples were collected from 93 patients at different stages of $\mathrm{HCV}$ infection at National Cancer Institute (NCI) and Hepatic Viruses Center - Teaching Hospital - Al Kasr El Eini - Cairo University. No patients were receiving any anti-viral treatment when enrolled in this study. Patients infected with virus B and liver autoimmune diseases were excluded. Sixteen healthy subjects were included as a control. The patients based on serologically documented $\mathrm{HCV}$ infection were categorized into three groups according to disease severity namely chronic ( $\mathrm{n}=25 ; 9$ males and 16 females), Cirrhosis $(n=27 ; 19$ males and 8 females), HCC $(n=25 ; 20$ males and 5 females) compared with Healthy control ( $n=16 ; 11$ males and 5 females). Patients of non-HCC included chronic and cirrhosis groups.

\section{Determination of Anti-HCV Antibodies}

Anti-HCV Abs were qualitatively measured in serum samples using an indirect ELISA kit (Murex Biotech S.A. (Pty) Ltd, Republic of South Africa).

\section{Determination of Hepatitis $B$ Surface Antigen (HBsAg)}


Quantitative measurement of $\mathrm{HBsAg}$ was done in serum with an indirect ELISA kit (Murex Biotech S.A. (Pty) Ltd, Republic of South Africa).

\section{Determination of liver enzymes}

Concentrations of aspartate aminotransferase (AST) and alanine aminotransferase (ALT) were assessed by programmed automated Bechman Synchron CX®9 clinical system (Marca REG, USA) according to the application sheets provided with the kits (spectrum diagnostic kits, MDSS GmbH, Germany).

\section{Cytokine assays}

Serum levels of IL-2, IL-10, IL-12, IL-1 $\beta$, IFN- $\alpha$, IFN- $\gamma$, and TNF- $\alpha$ R2 were measured by sandwich ELISA kit (eBioscience, San Diego, CA, USA). Serial dilutions of standards were prepared according to manufacture instructions. Then $100 \mu \mathrm{l}$ of diluted standard, $100 \mu \mathrm{l}$ of diluted serum samples were added, followed by the addition of $50 \mu \mathrm{l}$ of biotinconjugated to each well, and incubated for $2 \mathrm{~h}$ at room temperature (RT). After washing four times, $100 \mu \mathrm{l}$ of diluted streptavidin-HRP was added to each well, incubated for $1 \mathrm{~h}$ at RT. Following incubation, the microwell strips washed four times, $100 \mu 1$ of TMB substrate solution was pipetted to each well, incubated in protection from light between 10-25 minutes for color development, the substrate reaction is terminated by the addition of stop solution. Finally, the formed colored product is proportional to the quantity of human cytokine present in the serum and standard samples, measured at wavelength $450 \mathrm{~nm}$ by ELISA microplate reader (Sunrise, Tecan, Mannedorf, Switzerland).

\section{Statistical analysis}

The present data were analyzed by IBM statistical package for the social science version 24.0 (copyright by IBM SPSS software, US). All the raw data were normally distributed according to the Kolmogrov-
Smirnov test and the Shapiro-Wilk test and consequently the parametric statistical analysis was used. Two-way ANOVA was used to analyze the effect of sex, stages, and their interaction on the studied parameters, and then followed by post-hoc ANOVA (Duncan's test of homogeneity) to compare every two variables together. The regression analysis and Pearson's correlation coefficient (r) were used to estimate the relationship between the studied numerical dependant variables, whereas Spearman's correlation coefficient $\left(r_{s}\right)$ was used to estimate the relationship of non-numerical variables (stages). All data were expressed as a mean \pm standard error of the mean (SEM). Receiver Operating Characteristics (ROC) curve was done to estimate the best cut off point then a calculation of sensitivity, specificity, positive predictive value, and negative predictive value with their $95 \%$ confidence interval. A $P$-value less than 0.05 was considered statistically significant. All tests were two-tailed.

\section{Results}

\section{Clinical and biochemical parameters}

The demographic and biochemical characteristics of the subjects included in the study are shown in Table 1. The mean age of male hepatitis $\mathrm{C}$ patients was 49.78 in a chronic group, 51.74 in the cirrhosis group, and 57.10 in the HCC group compared to 45 in healthy control subjects. The percentage of male patients was $36 \%$ in the chronic group, $70.37 \%$ in the cirrhosis group, and $80 \%$ in the HCC group regarded as $68.75 \%$ in healthy controls. The mean age of female hepatitis $\mathrm{C}$ patients was 49.56 in a chronic group, 49.25 in the cirrhosis group, and 49.80 in the HCC group compared to 36.40 in healthy control subjects. The percentage of female patients was $64 \%$, $29.63 \%$, and $20 \%$ in groups of chronic, cirrhosis and HCC respectively regarded to $31.25 \% \%$ healthy controls. Concentrations of ALT and AST showed non-significant differences between males and 
females in all stages of liver disease. Although no significant differences were observed in the concentration of ALT between male patients of chronic and cirrhosis groups, the concentration of ALT in female patients of the cirrhosis group was significantly higher $(P<0.05)$ than in a chronic group. In the HCC group, the concentration of ALT in male patients was significantly higher than those of chronic and cirrhosis groups while female patients showed significantly higher levels $(P<0.05)$ than a chronic group. In both males and females, concentrations of AST in the cirrhosis and HCC group were significantly higher than those of the chronic group.

Table 1 Demographic and clinical data characteristics of control and patients infected with HCV at various stages of liver disease.

\begin{tabular}{cllll}
\hline & Control & \multicolumn{3}{c}{ Stages of liver disease } \\
\cline { 3 - 5 } & & Chronic & Cirrhosis & HCC \\
\hline Gender $(\%)$ & & & \\
Males & $11(68.75 \%)$ & $9(36 \%)$ & $19(70.37 \%)$ & $20(80 \%)$ \\
Females & $5(31.25 \%)$ & $16(64 \%)$ & $8(29.63 \%)$ & $5(20 \%)$ \\
Age & & & & \\
Males & $45 \pm 2.79$ & $49.78 \pm 2.02$ & $51.74 \pm 2.20$ & $57.10 \pm 1.06$ \\
Females & $36.40 \pm 4.70$ & $49.56 \pm 1.98$ & $49.25 \pm 2.80$ & $49.80 \pm 4.49$ \\
ALT (pg/ml) & & & & \\
Males & $22.64 \pm 1.58^{\mathrm{a}}$ & $42.33 \pm 1.73^{\mathrm{bc}}$ & $43.63 \pm 4.05^{\mathrm{bc}}$ & $58.30 \pm 4.09^{\mathrm{d}}$ \\
Females & $18.60 \pm 1.50^{\mathrm{a}}$ & $37.25 \pm 1.60^{\mathrm{b}}$ & $52.16 \pm 7.87^{\mathrm{cd}}$ & $59.00 \pm 5.68^{\mathrm{d}}$ \\
AST (pg/ml) & & & & \\
Males & $23.45 \pm 1.44^{\mathrm{a}}$ & $33.44 \pm 1.17^{\mathrm{a}}$ & $58.00 \pm 5.03^{\mathrm{b}}$ & $77.60 \pm 8.01^{\mathrm{bc}}$ \\
Females & $21.40 \pm 2.01^{\mathrm{a}}$ & $31.38 \pm 0.82^{\mathrm{a}}$ & $65.00 \pm 11.90^{\mathrm{bc}}$ & $84.60 \pm 10.86^{\mathrm{c}}$
\end{tabular}

Data are represented as mean \pm standard error of the mean.

Values with the same superscript letters in the row are similar (insignificantly differ, $\mathrm{P}>0.05$ ) whereas others did not (significant, $\mathrm{P}<0.05)$.ALT: alanine aminotransferase, AST: aspartate aminotransferase.

\section{Results of Two way ANOVA}

According to two way ANOVA, the mean levels of serum IL-2 is significantly affected by gender $\left(\mathrm{F}_{1,85}=\right.$ 46.05, $P<0.0001)$, stage $\left(\mathrm{F}_{3,85}=152.74, P<0.0001\right)$, stage and gender interaction $\left(\mathrm{F}_{3,85}=26.92, P<0.0001\right)$. Mean levels of serum IL-10 is insignificantly affected by gender $\left(\mathrm{F}_{1,85}=0.26, P \geq 0.05\right)$, while significantly affected by stage $\left(\mathrm{F}_{3,85}=126.373, P<0.0001\right)$, stage 
and gender interaction $\left(\mathrm{F}_{3,85}=17.12, P<0.0001\right)$. Also, mean levels of serum IL-12 is insignificantly affected by gender $\left(\mathrm{F}_{1,85}=0.52, P \geq 0.05\right)$, while significantly affected by stage $\left(\mathrm{F}_{3,85}=291.34, P<0.0001\right)$, stage and gender interaction $\left(\mathrm{F}_{3,85}=3.12, P<0.05\right)$. In addition, mean levels of serum IL-1 $\beta$ is significantly affected by gender $\left(\mathrm{F}_{1,85}=13.41, P<0.0001\right)$, stage $\left(\mathrm{F}_{3,85}=\right.$ 10.96, $P<0.0001)$, stage and gender interaction $\left(\mathrm{F}_{3,85}=\right.$ $3.83, P<0.05)$. The mean levels of serum IFN- $\alpha$ is significantly affected by gender $\left(\mathrm{F}_{1,85}=8.30, P<0.01\right)$, stage $\left(\mathrm{F}_{3,85}=4.62, P<0.01\right)$, stage and gender interaction $\left(\mathrm{F}_{3,85}=13.71, P<0.0001\right)$. The mean levels of serum IFN- $\gamma$ is insignificantly affected by gender $\left(\mathrm{F}_{1,85}=2.16, P \geq 0.05\right)$, while significantly affected by stage $\left(\mathrm{F}_{3,85}=18.07, P<0.0001\right)$, stage and gender interaction $\left(\mathrm{F}_{3,85}=2.51, P \geq 0.05\right)$. The mean levels of serum TNF- $\alpha \mathrm{R} 2$ is significantly affected by gender $\left(\mathrm{F}_{1,85}=6.11, P<0.05\right)$, stage $\left(\mathrm{F}_{3,85}=77.63, P<0.0001\right)$, stage and gender interaction $\left(\mathrm{F}_{3,85}=10.28, P<0.0001\right)$.

\section{Cytokine assays}

Cytokines were assessed in this study (Table 2), including Th1-mediated cytokines (IFN- $\gamma$ and IL-2), Th2-mediated cytokines (IL-10), and immuneregulatory cytokines (IFN- $\alpha, \mathrm{TNF}-\alpha \mathrm{R} 2$, and IL-12). In male and female patients of a chronic group, the mean levels of IL-2 were significantly $(P<0.05)$ increased compared to their corresponding cirrhosis and HCC groups. Within different groups of disease progression, male patients of chronic and cirrhosis groups recorded significant $(P<0.05$ and $P<0.0001)$ higher levels of IL-2 than in female patients of chronic and cirrhosis groups respectively. In male and female patients of a chronic group, the mean levels of IL-10 significantly exhibited higher levels than those of cirrhosis and HCC groups. Interestingly, in the chronic group, levels of IL-10 displayed higher significant $(P<0.05)$ values in males than females but levels of IL-10 in the stage of HCC were significantly $(P<0.05)$ higher in females than males. In male and female patients of a chronic group, the levels of IL-12 were significantly $(P<0.05)$ elevated compared to their corresponding cirrhosis and HCC groups. Moreover, levels of IL-12 showed no significant changes $(P \geq 0.05)$ between males and females of chronic, cirrhosis, and HCC groups. In male patients, mean levels of IL-1 $\beta$ were significantly $(P<0.05)$ increased in a chronic group than cirrhosis group while no significant changes have appeared in females between all disease stages groups.

Mean levels of IFN- $\alpha$ in males were significantly $(P<0.05)$ increased in a chronic group than those of the HCC group while levels of IFN- $\alpha$ in females showed no significant differences. In chronic and cirrhosis groups, the levels of IFN- $\alpha$ in females were significantly $(P<0.05$ and $P<0.0001)$ lesser than males respectively. In males, the levels of INF- $\gamma$ in the chronic group were significantly $(P<0.05)$ lesser than healthy controls while the HCC group exhibited significant $(P<0.05)$ higher levels than healthy controls while only females of the HCC group showed significant $(P<0.05)$ higher levels than healthy controls. Levels of IFN- $\gamma$ between males and females in the same group of patients revealed non-significant differences. In males and females of the cirrhosis group, the levels of serum TNF- $\alpha \mathrm{R}$ were significantly $(P<0.05)$ increased compared to their corresponding healthy controls, cirrhosis, and $\mathrm{HCC}$ groups of patients. Levels of TNF- $\alpha \mathrm{R}$ in females were significantly higher than males of a chronic group 
while were significantly $(P<0.05)$ lesser than males of the cirrhosis group.

Table 2 The levels ( $\mathrm{pg} / \mathrm{ml}$ ) of the measured cytokines in healthy controls and hepatitis $\mathrm{C}$ patients in various stages of liver disease.

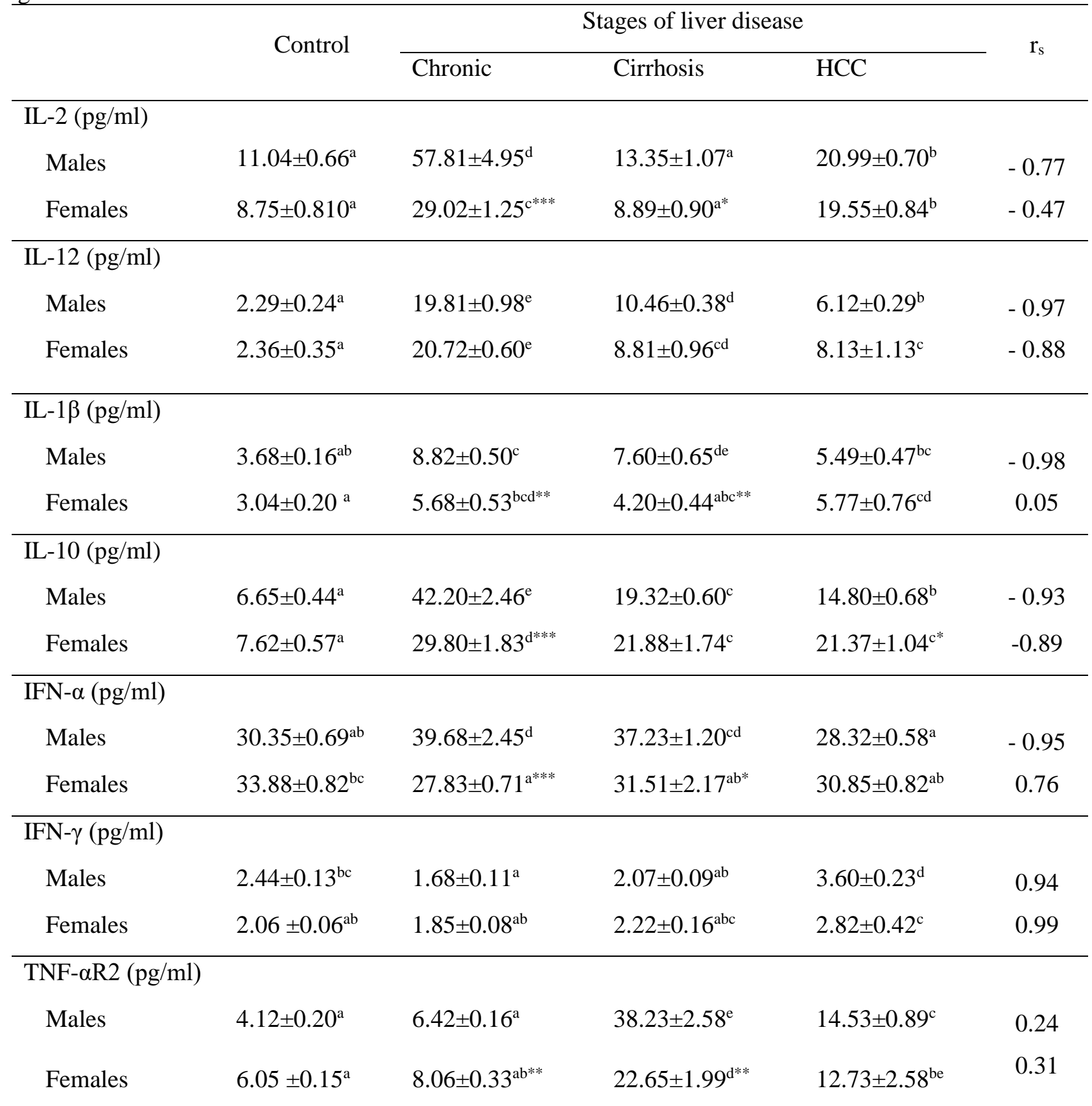

Data are represented as mean \pm SEM.

Values with the same superscript letters in the same row are similar (insignificantly differ, $\mathrm{P} \geq 0.05$ ) whereas others did not (significant, $P<0.05$ ).

*: significant difference $(P<0.05)$ in comparison to the corresponding male for the same variable.

**: significant difference $(P<0.005)$ in comparison to the corresponding male for the same variable $* * *$ : significant difference $(P<0.0001)$ in comparison to the corresponding male for the same variable. $r_{s}$ : Spearman's correlation coefficient. 
Relationships between levels of cytokines and various stages of hepatitis $C$

Serum levels of IL-2 and either IL-10 or IL-12 were negatively correlated in either males $\left(r_{s}=-0.77, r_{s}=-\right.$ 0.93, and $\left.r_{s}=-0.97\right)$ or female $\left(r_{s}=-0.47, r_{s}=-0.89\right.$, and $\left.r_{s}=-0.88\right)$ patients with different stages of liver disease progression (groups of chronic, cirrhosis, and HCC, respectively) (Table 2). In contrast, serum levels of IFN- $\gamma$ and TNF- $\alpha \mathrm{R} 2$ were positively correlated with stages of liver disease progression in both genders. Interestingly, serum levels of IFN- $\alpha$ showed an inverse correlation in male patients $(r=-$ $0.95)$ and positive correlation in female patients $\left(r_{s}=\right.$ 0.76) with different stages of hepatitis C. In the same manner, serum levels of IL-1 $\beta$ showed an inverse correlation in male patients $\left(r_{s}=-0.98\right)$ and positive correlation in female patients $\left(r_{s}=0.05\right)$ with different stages of liver disease progression.

\section{Relationship between the levels of various cytokines}

As shown in Figure 1, the values of correlations and they are significant are presented. There was a direct and significant correlation $(\mathrm{r}=0.56, \quad P=0.023)$ between the levels of IL-1 $\beta$ and IFN- $\gamma$ in female patients of the chronic group. In cirrhosis group, the levels of IFN- $\gamma$ and IL-10 were positively and significantly correlated $(\mathrm{r}=0.53, P=0.018)$ in males while females showed an inverse significant correlation between the levels of IL-2 and either IFN$\gamma(\mathrm{r}=-0.88, P=0.004)$ or TNF- $\alpha \mathrm{R} 2(\mathrm{r}=-0.71, P=$
$0.047)$ as well as IL-10 and IL-12 $(\mathrm{r}=-0.83, P=0.01)$. On the other hand, a direct significant correlation between IL-1 $\beta$ and TNF- $\alpha \mathrm{R} 2(\mathrm{r}=0.86, P=0.005)$ was observed in females of the cirrhosis group. In the HCC group, there was a direct relationship was observed significantly $(\mathrm{r}=0.01, P=0.94)$ between the levels IFN- $\gamma$ and TNF- $\alpha$ R2. The data of Pearson correlation that failed to show any significant correlations between the cytokines are not shown.

\section{Correlation between the levels of AST or ALT and} the cytokines

The relation between serum liver function markers and cytokine levels is demonstrated in Figure 2. Concentrations of AST were significantly correlated with the levels of TNF- $\alpha \mathrm{R} 2(\mathrm{r}=-0.592, P=0.006)$ in male patients of the HCC group. There was a positive significant correlation between the levels of ALT and IL-12 ( $\mathrm{r}=0.698, P=0.037)$ in male patients of the chronic group. Also, the spearman correlation showed that serum levels of ALT were directly significantly related to IL- $\beta$ ( $r=0.537, P=0.032)$, and inversely significantly related to TNF- $\alpha \mathrm{R} 2(\mathrm{r}=-0.561, P=$ 0.024 ,) in female patients of chronic group. In male patients of the cirrhosis group, the levels of ALT were significantly correlated with IL-2 with an inverse relationship $(\mathrm{r}=-0.585, P=0.009)$. The other correlations that were not shown revealed a nonsignificant association in either males or females of the studied groups. 



Figure 1 The relation between serum levels of cytokines $(\mathrm{pg} / \mathrm{ml})$ in male and female patients at different stages of liver disease. $r=$ correlation coefficient. 

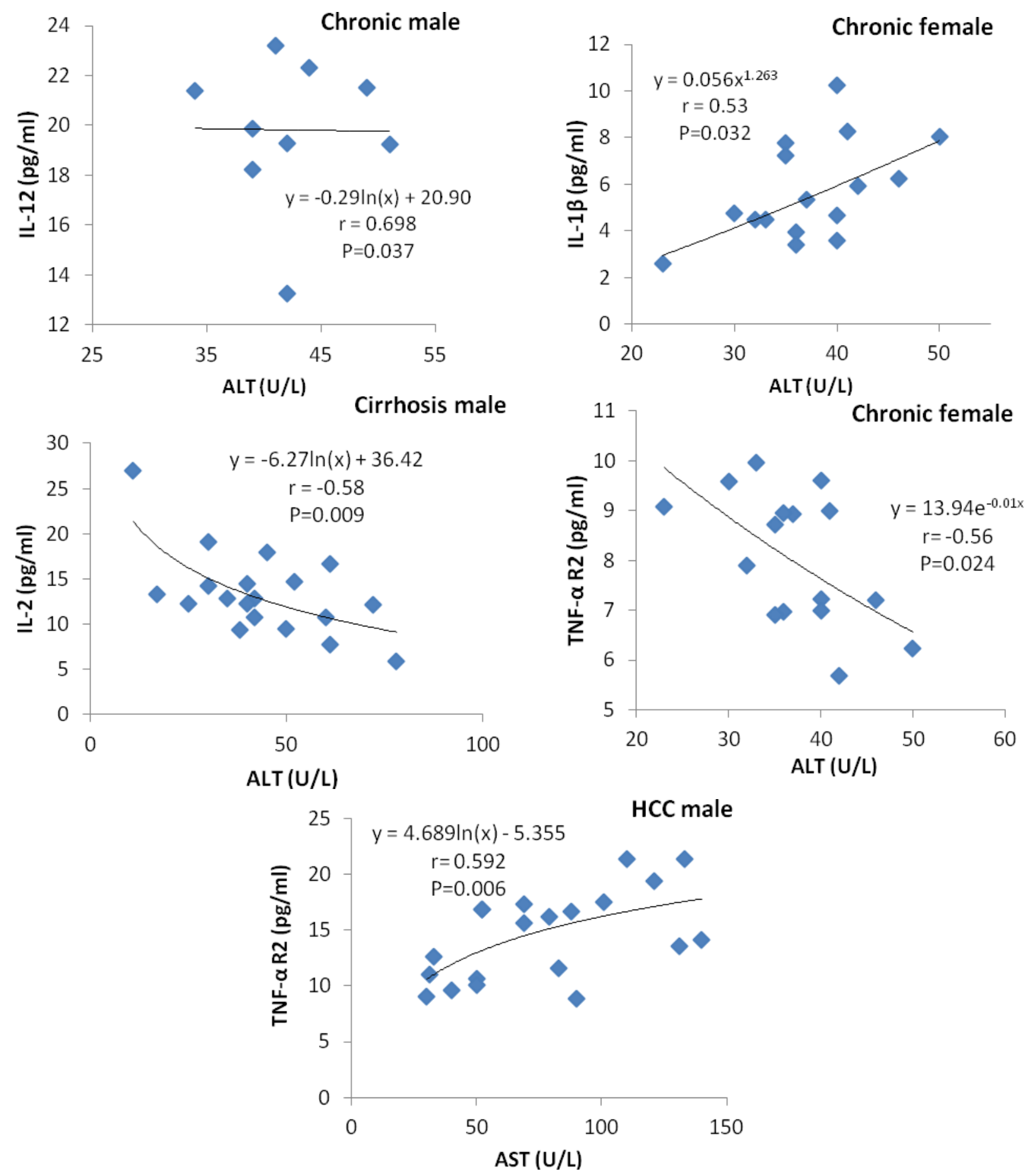

Figure 2 The relation between serum levels of cytokines (pg/ml) and levels of ALT (U/L) and AST (U/L) in male and female patients at different stages of liver disease. $r=$ correlation coefficient. 


\section{ROC analysis and stages of liver disease}

The data obtained from ROC curve analysis for the characteristic cytokines for each stage of liver disease. Among the investigated cytokines, serum levels of IFN- $\gamma$, AST, and ALT were upregulated in male patients of the HCC group compared to non-HCC patients (Table 3 and Figure 3A). Levels of IFN- $\gamma$ recorded the greatest AUC (0.918) when a cutoff of $2.7(\mathrm{pg} / \mathrm{ml})$ was selected to define a patient with $\mathrm{HCC}$, the sensitivity, specificity, PPV, NPV, and accuracy were $85 \%, 90 \%, 81 \%, 92 \%$, and $88 \%$, respectively. The AUCs for AST and ALT were 0.810 and 0.803, with cutoff 48.5 and 49.5 , respectively. A serum ALT concentration greater than $49.5 \mathrm{pg} / \mathrm{mL}$ had a sensitivity of $70 \%$, a specificity of $80 \%$, accuracy $76 \%$, NPV $84 \%$, PPV $64 \%$ to diagnose male patients with HCC from infected hepatitis $\mathrm{C}$ patients in chronic and cirrhosis stages; a serum concentration of AST equal to or higher than $48.5 \mathrm{pg} / \mathrm{ml}$ had a sensitivity of $80 \%$, a specificity of $77 \%$, accuracy $78 \%$, NPV $89 \%$, PPV $73 \%$ to discriminate male HCC patients from non-HCC patients. Within the other down-regulated cytokines, the AUC for IFN- $\alpha$ (0.876) was lower than IL-12 (0.712) and IL-10 (0.651), respectively. At the cut-off value of $29.6 \mathrm{pg} / \mathrm{ml}$ for IFN- $\alpha$, the sensitivity, specificity, NPV, and PPV reached $80 \%, 857 \%, 89 \%, 73 \%$, respectively. The cutoff value for IL-12 $(7.75 \mathrm{pg} / \mathrm{mL})$ recorded sensitivity of $90 \%$, a specificity of $72 \%$, accuracy $78 \%$, NPV of $93 \%$, PPV of $62 \%$. Serum levels of IL-10 at cut-off value $(15.95 \mathrm{pg} / \mathrm{ml})$, had a sensitivity of $75 \%$, a specificity of $67 \%$, accuracy $69 \%$, NPV $84 \%$, PPV $54 \%$. In females, the ROC analysis has drawn for the downregulation in the levels of ALT, AST, and IFN- $\gamma$ displayed AUC of 0.862, 0.897, and 0.779, respectively to discriminate female patients with HCC from the other stages of hepatitis $\mathrm{C}$ infection (Table 4 and Figure 3B). A cut-off value for ALT (47 pg/ml) and AST $(50 \mathrm{pg} / \mathrm{ml})$ concentrations reached $100 \%$ for sensitivity, while specificity, accuracy, NPV, and PPV were $80 \%, 82 \%, 89 \%$ and $51 \%$ for ALT and $83 \%$, $85 \%, 100 \%$, and $50 \%$, for AST. In contrast to males, there are not any down-regulated markers related to acquiring HCC in females

Table 3 ROC curve values of studied markers and cytokines between male patients with HCC and non-HCC.

\begin{tabular}{ccccccc}
\hline & \multicolumn{3}{c}{ Upregulation } & \multicolumn{3}{c}{ Downregulation } \\
\cline { 2 - 7 } & ALT & AST & IFN- $\gamma$ & IL-10 & IL-12 & IFN- $\alpha$ \\
\hline Sensitivity & $70 \%$ & $80 \%$ & $85 \%$ & $75 \%$ & $90 \%$ & $80 \%$ \\
Specificity & $80 \%$ & $77 \%$ & $90 \%$ & $67 \%$ & $72 \%$ & $85 \%$ \\
AUC & 0.803 & 0.810 & 0.918 & 0.651 & 0.712 & 0.876 \\
Accuracy & $76 \%$ & $78 \%$ & $88 \%$ & $69 \%$ & $78 \%$ & $83 \%$ \\
PPV & $64 \%$ & $64 \%$ & $81 \%$ & $54 \%$ & $62 \%$ & $73 \%$ \\
NPV & $84 \%$ & $88 \%$ & $92 \%$ & $84 \%$ & $93 \%$ & $89 \%$ \\
Cut-off & 49.5 & 48.5 & 2.7 & 15.95 & 7.75 & 29.6 \\
$P$ value & $<0.001$. & $<0.001$ & $<0.001$ & 0.59 & $<0.008$ & $<0.001$ \\
$95 \% \mathrm{Cl}$ & $0.684-0.921$ & $0.694-0.925$ & $0.834-1.0$ & $0.508-0.794$ & $0.572-0.853$ & $0.788-0.965$ \\
\hline
\end{tabular}

ROC, receiver-operating characteristic; AUC, area under the curve; NPV, negative predictive value; PPV, positive predictive value. CI: confidence interval. 
Table 4 ROC curve values of studied cytokines between female HCC and non-HCC patients.

\begin{tabular}{llll}
\hline & \multicolumn{3}{c}{ Upregulation } \\
\cline { 2 - 4 } & ALT & AST & IFN- $\gamma$ \\
\hline Sensitivity & $100 \%$ & $100 \%$ & $60 \%$ \\
Specificity & $80 \%$ & $83 \%$ & $93 \%$ \\
AUC & 0.862 & 0.897 & 0.779 \\
Accuracy & $82 \%$ & $85 \%$ & $88 \%$ \\
PPV & $51 \%$ & $50 \%$ & $60 \%$ \\
NPV & $89 \%$ & $100 \%$ & $93 \%$ \\
Cut-off & 47 & 50 & 2.47 \\
P value & 0.11 & 0.005 & 0.49 \\
95\% Cl & $0.73-0.98$ & $0.78-1.0$ & $0.54-1.0$ \\
\hline
\end{tabular}

ROC, receiver-operating characteristic; AUC, area under the curve; NPV, negative predictive value; PPV, positive predictive value, $\mathrm{CI}$ : confidence interval

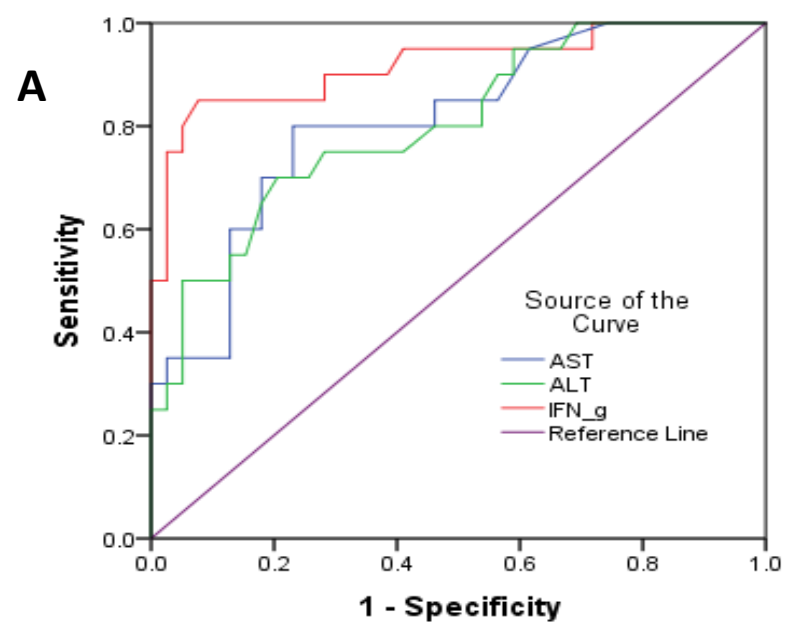

Diagonal segments are produced by ties.

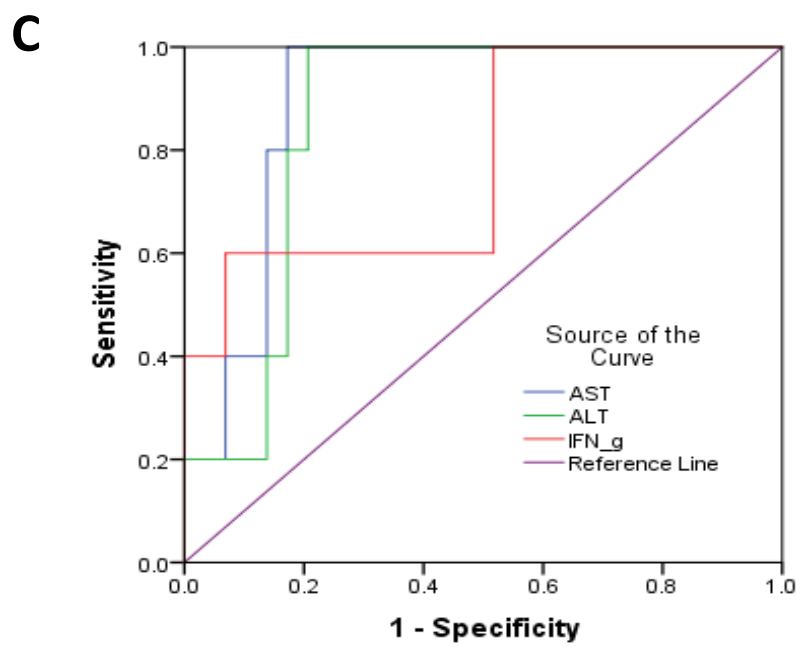

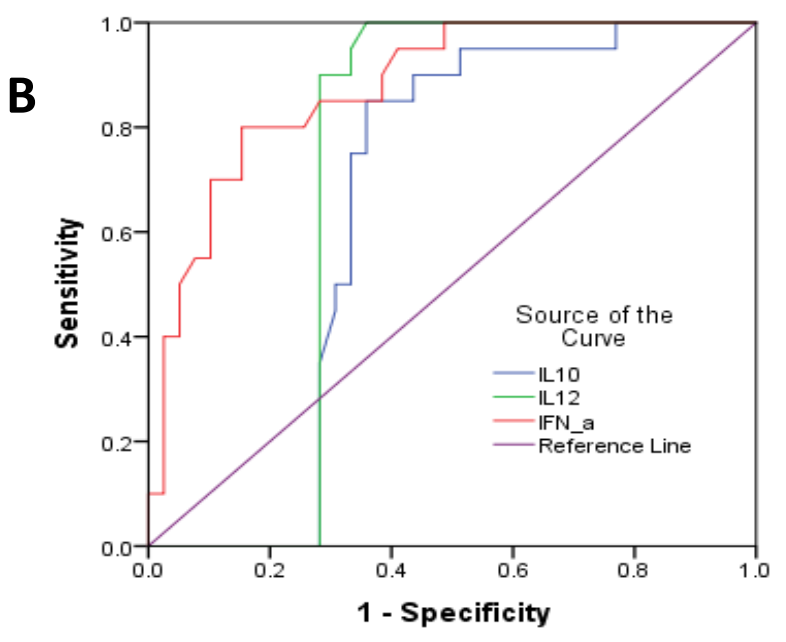

Diagonal segments are produced by ties.

Figure 3. (A) Receiver Operating Characteristics (ROC) Curve analysis for up-regulated markers related to acquiring $\mathrm{HCC}$ in males in comparison to other studied patients (non-HCC). (B) ROC Curve analysis for down-regulated markers related to acquiring $\mathrm{HCC}$ in males in comparison to other studied patients (non-HCC). (C) ROC Curve analysis for up-regulated markers related to acquiring $\mathrm{HCC}$ in females in comparison to other studied patients (non-HCC). 


\section{Discussion}

In $\mathrm{HCV}$ infection, CD4+T cells are considered key players of an adaptive immune response, providing help in activating cytotoxic and humoral responses. Production of Th1-associated cytokines such as IFN- $\gamma$ promotes recruitment of neutrophil and macrophage leading inflammatory responses. Generation of IL-4 and IL-10 as a Th2 cytokine can diminish Th1 associated response and developing a humoral response (Moser and Murphy, 2000). IL-2 is a monomeric glycoprotein, mainly produced by activated CD4+ $\mathrm{T}$ cells, CD8+ $\mathrm{T}$ cells, and dendritic cells. IL-2 is a potent proinflammatory cytokine that is involved in the differentiation of effector CD4+ $\mathrm{T}$ cells into Th1 producing TNF- $\alpha$ and IFN- $\gamma$ (D'Souza and Lefrancois, 2003). Moreover, IL-2 influences cell survival, differentiation, and the formation of immune memory cells and represented a negative modulator of immune activation. Data described the serum levels of IL-2 were controversial. Previous reports indicated an increase in the serum levels of IL-2 of HCV-infected patients as compared to the control group (Fan et al., 2000). The present results revealed that serum levels of IL-2 in both males and females of chronic and HCC groups were significantly higher than healthy controls respectively. However, serum levels of IL-2 in both sexes of the cirrhosis group showed no significant differences in comparison to controls. Zhang et al. (2011) documented a reduction in the serum levels of IL-2 in HCV-infected patients. Here, a comparison of IL-2 levels between males and females in the stages of liver disease showed that serum levels of IL-2 in female patients were significantly lower than those in males of chronic and cirrhosis groups (Zhang et al., 2011). Also, de Souza-Cruz et al. (2016) reported that a high percentage of $\mathrm{HC}$ patients with moderate and severe fibrosis displayed elevated levels of IL-2, suggesting its participation in the development of severe fibrosis (de Souza-Cruz et al., 2016).

IL-12 is a heterodimer consisted of p40 and p35 subunits. IL-12 has immunoregulatory functional activities and is primarily secreted by antigen- presenting cells. Production of IL-12 modulates the innate immune responses and shapes the phenotype of adaptive responses. It represents a critical step in the polarization of naive $\mathrm{T}$ cells into Th1 immune response that is essential for infection clearance, induces secretion of IFN- $\gamma$ and TNF- $\alpha$, and promotes differentiation of CD4+ T cells towards Th1 type (Vasconcellos et al., 2011). In the present study, the serum levels of IL-12 were significantly higher $(P<$ 0.05 ) in either males or females of the three liver disease groups compared to healthy controls. However, no significant differences were noticed in the levels of IL-12 between males and females in all studied groups. These data are following other reports which indicated a significant elevation of IL-12 levels in patients with chronic $\mathrm{HCV}$ infection than in healthy donors (Sarih et al., 2000). However, there are controversial data about the role of IL-12 in viral infection. Previous studies pointed to the increase of IL-12 level by disease progression suggesting its contribution in the developmental steps of hepatic injury in patients with chronic hepatitis $\mathrm{C}$ (Gigi et al., 2008). Here, in both males and females of HCC patients, the serum levels of IL-12 were decreased by disease progression of the liver. The higher expression of this proinflammatory in a chronic group compared to cirrhosis and HCC groups suggests participating in viral clearance, but not in the pathogenesis of the liver disease.

IL- $1 \beta$ is synthesized as an inactive cytoplasmic precursor which is further processed to its mature active form by activated caspase-1 (Tschopp et al., 2003). HCV infection stimulates IL-1 $\beta$ secretion that promotes NF- $\kappa \mathrm{B}$ required for the transcriptional upregulation of IL-1 $\beta$. Burdette et al. (2012) observed the transcriptional stimulation and secretion of IL- $1 \beta$ from $\mathrm{HCV}$-infected cells. Moreover, a significant increase in the level of IL-1 $\beta$ has been documented in $\mathrm{HCV}$ and liver cirrhosis patients compared to healthy controls (Burdette et al., 2012). Our results are consistent with these findings where the inflammatory IL-1 $\beta$ levels were increased significantly in male 
patients of chronic and cirrhosis groups than those in healthy controls. In female patients, levels of IL- $1 \beta$ were significantly higher in both chronic and HCC groups than those in healthy controls. Female patients of the cirrhosis group had significant $(P<0.01)$ lower levels of IL-1 $\beta$ than males of the cirrhosis group. Furthermore, in both male and female patients of HCC, a positive correlation was noticed between levels of IL- $1 \beta$ and disease progression of the liver. These results are in agreement with Gieling et al. (2009) who stated that this cytokine involved in the progression of liver injury to fibrosis, could be considered an indication of chronic infection that leads to liver cirrhosis and HCC. As a pleiotropic inflammatory factor, IL-1 $\beta$ has also been implicated in promoting tissue pathology and inducing the production of profibrogenic mediators (Chakraborty et al., 2010), thereby emphasized its possible function in $\mathrm{HCV}$ infection.

IL-10 is considered a pleiotropic cytokine that can induce and inhibit immune responses. It is secreted by Th2 cells, however, can be produced by other immune cells like monocytes, macrophages, NK cells, and dendritic cells (Ouyang et al., 2011). IL-10 is a potent anti-inflammatory cytokine, its major role in diminishing host immune response to pathogens could hinder the damage to the host and maintaining normal tissue homeostasis (Sabat et al., 2010). In contrast, some pathogens can use the immunosuppressive characteristics of IL-10 to outline host immune response that leads to persistent infection (Brooks, 2006). Persistent or chronicity of HCV infection can be facilitated by a conserved mechanism of hostregulated immunosuppression that is supposed to downregulate $\mathrm{T}$ cell function. CD4+ T cells and CD8+ $\mathrm{T}$ cells lose their effector functions to control viral infections (Wherry, 2011). CD8+ T cells become unable to secrete antiviral cytokines, to kill virally infected cells, and their proliferation capacity in context to antigen stimulation is lost. Similarly, the cytokine secretion by CD4+ T cells is impaired and associated with insufficient proliferation power
(Brooks et al., 2005). Production of systemic elevated concentrations of IL-10 suggests its conserved mechanism in the progression towards persistent viral infections (Wilson and Brooks, 2011). This immune response of IL-10 was confirmed in the current study where male and female patients of the chronic group demonstrated significantly higher $(P<0.05)$ levels of IL-10 compared to males and females of the normal control group respectively. Additionally, several reports stated the increase of IL-10 in serum of HCV patients as compared to the control group and demonstrated greater spontaneous IL-10 production by peripheral blood mononuclear cells in patients either with chronic hepatitis or liver cirrhosis than in healthy controls (El-Emshaty et al., 2015). IL-10 shared a regulatory function through downregulation in expression levels of MHC-II and co-stimulatory molecules on antigen-presenting cells, and diminished expression of co-molecule stimulatory CD28 that inhibits T-cell activation. HCV infection is characterized by continual high levels of IL-10 that may be assumed to activation suppressing regulatory $\mathrm{T}$ cells in a trial to overcome fibrosis, thereby inhibit the proper immune response against virus infection (Mege et al., 2006). On the opposite side, the lower levels of this cytokine may produce inflammatory responses that cause extreme damage to liver tissue. This assumption was inconsistent with our data where the serum levels of IL-10 in both male and female patients of the cirrhosis group were significantly lower levels than those in the chronic group. Aroucha et al. (2013) indicated the protective role of IL-10 in patients with moderate fibrosis, reinforcing our hypothesis that IL-10 plays a protective function during $\mathrm{HCV}$ infection concerning liver fibrosis development (Aroucha et al., 2013). Other studies have underlined this preferential function of IL-10 when utilized as a therapy for chronic $\mathrm{HCV}$, which minify the severity of fibrosis in enrolled individuals (Nelson et al., 2000). Other experimental animal studies demonstrated that loss of IL-10 production was linked with liver fibrosis (de Souza-Cruz et al., 
2016). In contrast to the previous data, Abayli et al. (2003) revealed the absence of correlation between IL-10 expression levels and histological activity (Abayli et al., 2003). In the present work, only males of the HCC group showed a significant decrease $(\mathrm{P}<$ 0.05 ) in serum levels of IL-10 compared to males of the cirrhosis group while females showed nonsignificant differences. On the other hand, serum levels of IL-10 were still significantly higher than in the normal control group. The explanation for these findings may be attributed to that the high serum IL10 levels in patients with HCC based on the generation of IL-10 by tumor cells, moreover the production at the site of inflammatory changes with activated infiltrating mononuclear cells in the liver (Zekri et al., 2005). The immunosuppressive activities of IL-10 supposed to effectively participate in the development of neoplasm by the termination of macrophage activation and IFN- $\gamma$ production, thus reflect the state of obstruction no two potential immune mediators of an antitumor response; this may offer a chance for the tumor cells to escape the host immune surveillance (Othman et al., 2013). Also, IL10 recognition to its receptors on tumor cells could subsequently hinder the programmed cell death and provoke the proliferation of tumor cells. Therefore, it has been suggested that IL 10 has an important role in the oncogenetic and metastatic power of neoplasms (Hsia et al., 2007). Here, serum levels of IL-10 showed a higher positive correlation with liver disease progression in females $(r=0.46)$ than males $(r=0.01)$. In another study, IL-10 showed significant elevation with disease progression, and the highest expression was detected in HCC compared to liver cirrhosis $(P<$ 0.0001) (El-Emshaty et al., 2015).

IFNs are a family of cytokines secreted by cells of the host as a consequence of various infections like viruses which stimulate the protective mechanisms of the immune system. An innate immune response is the first line of defense against viruses, and IFNs are the major cytokines involved in induction, activation, and organization of the antiviral effect of innate immune cells such as natural killer cells (NKCs) (Stetson and Medzhitov, 2006). IFN- $\alpha$ is a type I IFNs that is produced by most types of cells that are infected with a virus and also by central guardian cells of the innate immune system such as macrophages and dendritic cells. Serum levels of IFN- $\alpha$ were significantly higher $(\mathrm{P}<0.05)$ in males of a chronic group than those in males of normal control. However, with liver disease progression, serum levels of IFN- $\alpha$ demonstrated an inverse correlation in females $(\mathrm{r}=0.76)$ followed by males $(r=-0.95)$. IFN- $\gamma$ is a type II of IFNs, secreted by certain cells of the immune system like NKCs and natural killer $\mathrm{T}$ cells, which represents a portion of the innate immune response, as well as antigen-specific $\mathrm{T}$ cells including CD4+ Th1 and CD8+ cytotoxic T cells. In the current work, only male patients of the chronic group displayed significantly lower $(P<0.05)$ levels of IFN- $\gamma$ than those in males of normal control respectively. Additionally, levels of IFN- $\gamma$ increased with liver disease progression, males of the HCC group recorded a significant increase in the levels of IFN- $\gamma$ compared to chronic $(P<0.05)$ and cirrhosis $(P<0.05)$ groups.

TNF- $\alpha$ has two types of receptors, subsequent binding of TNF- $\alpha$ to its receptor followed by dissociation from the surface of the target cells. The shaded receptors can be estimated in serum as soluble TNF- $\alpha$ receptor I (sTNFR-I, p55, CD120A) and soluble TNF- $\alpha$ receptor II (sTNFR2-II, p75, CD120B), and have a longer half-life than TNF- $\alpha$ itself (Riordan et al., 2003). The soluble TNF- $\alpha$ receptors have been engaged in various liver diseases, TNFR-II provokes immunomodulatory actions (Tarrats et al., 2011). The serum levels of these receptors express on severity degree of inflammation in the liver of chronic hepatitis C. Furthermore, the levels of sTNFR-II could be considered as a prognostic marker for death rate in liver cirrhosis (Grunhage et al., 2008). In the current work, the serum levels of sTNF- $\alpha$ RII in both male and female patients of the cirrhosis group were significantly higher $(P<$ $0.05)$ than those in males and females of chronic and 
HCC groups respectively. These results are in agreement with (Zekri et al., 2016) who found that serum level of sTNF-RII was significantly higher in patients with liver cirrhosis than in HCC patients $(\mathrm{P}<$ $0.001)$.

Among the upregulated cytokines in males, the ROC curve analysis of the individual markers and cytokines revealed that the serum level of IFN- $\gamma$ had valuable diagnostic accuracy in discriminating the male HCC patients from all other patients, as the AUC was in the range of (0.918), and fair diagnostic accuracy in discriminating the HCC group from the Non-HCC group. However, among downregulated cytokines, INF- $\alpha$ has AUC equal to 0.876. This result suggests that IFN- $\gamma$ may be utilized as a diagnostic marker for the early detection of HCC in males of the normal population and infected HCV patients.

\section{Conclusion}

The present study gives a spotlight on the expression pattern of Th1-, Th2-, and immunoregulatory-related cytokines that existed in $\mathrm{HCV}$ infection during chronic hepatitis, cirrhosis, and HCC stages which confirm our previous study (Zekri et al., 2018). In both genders of $\mathrm{HCV}$ patients during disease progression of liver disease, levels of IL-12 and IL-10 were significantly higher than those in corresponding healthy subjects. Moreover, the gender difference affects the pattern milieu of these cytokines whereas the levels of IL-2, IL-1 $\beta$, IFN- $\alpha$ in the chronic and cirrhosis stages were markedly decreased in females compared to males in the same stage. Also, levels of IL-10 showed significantly lower levels in females during the chronic infection stage of HCV compared to males. Overall, investigation of the pattern of cytokine expression may assist to consider a new vision for the differences in the pathogenesis of $\mathrm{HCV}$ infection according to gender during liver disease progression. These cytokines are suggested to be used as a biomarker for early diagnosis of HCC stage.

\section{Conflict of interest statement}

The authors have no conflict of interest.

\section{Financial support}

This study was supported by the Faculty of Science, Cairo University, Egypt.

\section{References}

[1] Lin MV, King LY, Chung RT. Hepatitis C virus-associated cancer. Annu Rev Pathol 2015; 10:345-70.

[2] Steinke JW, Borish L. Cytokines and chemokines. J Allergy Clin Immunol 2006; 117(2):441-5.

[3] Jordan SJ, Gupta K, Ogendi BM, Bakshi RK, Kapil R, Press CG, Sabbaj S, Lee JY, Geisler WM. The Predominant CD4+ Th1 Cytokine Elicited to Chlamydia trachomatis Infection in Women Is Tumor Necrosis Factor Alpha and Not Interferon Gamma. Clin Vaccine Immunol 2017; 24(4):10-17.

[4] Hurdayal R, Ndlovu HH, Revaz-Breton M, Parihar SP, Nono JK, Govender M, Brombacher F. IL-4-producing $\mathrm{B}$ cells regulate $\mathrm{T}$ helper cell dichotomy in type 1- and type 2-controlled diseases. Proc Natl Acad Sci U S A 2017; 114(40): E8430-39.

[5] Paul WE, Zhu J. How are TH2-type immune responses initiated and amplified?. Nat Rev Immunol 2010; 10(4): 225-35.

[6] Zhang L, Hao CQ, Miao L, Dou XG. Role of Th1/Th2 cytokines in serum on the pathogenesis of chronic hepatitis $\mathrm{C}$ and the outcome of interferon therapy. Genet Mol Res. 2014; 13 (4): 9747-55.

[7] Wald O, Weiss ID, Galun E, Peled A. Chemokines in hepatitis $\mathrm{C}$ virus infection: pathogenesis, prognosis, and therapeutics. Cytokine 2007; 39 (1): 50-62.

[8] Moser M and Murphy KM. Dendritic cell regulation of TH1-TH2 development. Nature Immunology 2000;1(3):199-205

[9] D'Souza WN, Lefrancois L. IL-2 is not required for the initiation of $\mathrm{CD} 8 \mathrm{~T}$ cell cycling but 
sustains expansion. J Immunol 2003; 171 (11): 572735.

[10] Fan X, Liu W, Li C. Determination of serum cytokines in individuals with $\mathrm{HCV}$ infection. Zhonghua Shi Yan He Lin Chuang Bing Du Xue Za Zhi 2000; 14(2):145-7.

[11] Zhang L, Miao L, Han F, Dou XG. Cytokine levels in serum of patients with chronic hepatitis $\mathrm{C}$ and its significance. Xi Bao Yu Fen Zi Mian Yi Xue Za Zhi 2011; 27(3):301-3.

[12] de Souza-Cruz S, Victória MB, Tarragô AM, da Costa AG, Pimentel JP, Pires EF, Araújo Lde P, Coelho-Dos-Reis JG, Gomes Mde S, Amaral LR, Teixeira-Carvalho A, Martins-Filho OA, Victória Fda S, Malheiro A. Liver and blood cytokine microenvironment in $\mathrm{HCV}$ patients is associated to liver fibrosis score: a proinflammatory cytokine ensemble orchestrated by TNF and tuned by IL- 10 . BMC Microbiol 2016; 16: 3

[13] Vasconcellos R, Carter NA, Rosser EC, Mauri C. IL-12p35 subunit contributes to autoimmunity by limiting IL-27-driven regulatory responses. J Immunol 2011; 187(6):3402-12.

[14] Sarih M, Bouchrit N, and Benslimane A,

"Different cytokine profiles of peripheral blood mononuclear cells from patients with persistent and self-limited hepatitis C virus infection," Immunology Letters, vol. 74, no. 2, pp. 117-120, 2000

[15] Gigi E, Raptopoulou-Gigi M, Kalogeridis A, "Cytokine mRNA expression in hepatitis $\mathrm{C}$ virus infection: $\mathrm{TH} 1$ predominance in patients with chronic hepatitis $\mathrm{C}$ and $\mathrm{TH} 1$ - $\mathrm{TH} 2$ cytokine profile in subjects with a self-limited disease," Journal of Viral Hepatitis, vol. 15, no. 2, pp. 145-154, 2008

[16] Tschopp J, Martinon F, Burns K. NALPs: a novel protein family involved in inflammation. Nat Rev Mol Cell Biol 2003; 4(2): 95-104.
[17] Burdette D, Haskett A, Presser L, McRae S, Iqbal J, Waris G. Hepatitis $\mathrm{C}$ virus activates interleukin- $1 \beta$ via caspase-1-inflammasome complex. J Gen Virol 2012; 93(Pt 2): 235-46.

[18] Gieling RG, Wallace K, Han YP. Interleukin1 participates in the progression from liver injury to fibrosis. Am J Physiol Gastrointest Liver Physiol 2009; 296(6): G1324-31.

[19] Chakraborty S, Kaushik DK, Gupta M, Basu A. Inflammasome signaling at the heart of central nervous system pathology. J Neurosci Res 2010; 88(8): 1615-31.

[20] Ouyang W, Rutz S, Crellin NK, Valdez PA, Hymowitz SG. Regulation and functions of the IL-10 family of cytokines in inflammation and disease. Annu Rev Immunol 2011;29:71-109.

[21] Sabat R, Grutz G, Warszawska K, Kirsch S, Witte E, Wolk K, Geginet J. Biology of interleukin10. Cytokine Growth Factor Rev 2010; Oct; 21(5):331 44.

[22] Brooks DG. Interleukin-10 determines viral clearance or persistence in vivo. Nature Med 2006; 12:1301-9.

[23] Wherry EJ. T cell exhaustion. Nature Immunology 2011;12(6):492-99.

[24] Brooks DG, Teyton L, Oldstone MBA, and McGavern DB. Intrinsic functional dysregulation of CD4 T cells occurs rapidly following persistent viral infection. Journal of Virology 2005;79(16):10514-27.

[25] Wilson EB and Brooks DG. The role of IL-10 in regulating immunity to persistent viral infections. Current topics in microbiology and immunology 2011;350: 39-65.

[26] El-Emshaty HM, Nasif WA, Mohamed IE. Serum Cytokine of IL-10 and IL-12 in Chronic Liver Disease: The Immune and Inflammatory Response. Dis markers 2015; 2015:707254 
[27] Mege JL, Meghari S, Honstettre A, Capo C, Raoult D. Two faces of interleukin 10 in human infectious diseases. Lancet Infect Dis 2006; 6(9):55769.

[28] Aroucha DC, do Carmo RF, Moura P, Silva JL, Vasconcelos LR, Cavalcanti MS. High tumor necrosis factor-a/interleukin-10 ratio is associated with hepatocellular carcinoma in patients with chronic hepatitis C. Cytokine 2013;62(3):421-5.

[29] Nelson DR, Lauwers GY, Lau JY, Davis GL. Interleukin 10 treatment reduces fibrosis in patients with chronic hepatitis $\mathrm{C}$ : a pilot trial of interferon nonresponders. Gastroenterol 2000;118(4):655-660.

[30] Abayli B, Canataroglu A, Akkiz H. Serum profile of T helper 1 and T helper 2 cytokines in patients with chronic hepatitis $\mathrm{C}$ virus infection. Turk J Gastroenterol 2003; 14(1):7-11.

[31] Zekri AR, Ashour MS, Hassan A, Alam El-Din HM, El-Shehaby AM, Abu-Shady MA. Cytokine profile in Egyptian hepatitis $\mathrm{C}$ virus genotype-4 in relation to liver disease progression. World $\mathrm{J}$ Gastroenterol 2005; 11(42)6624-30.

[32] Othman MS, Aref AM, Mohamed AA, Ibrahim WA. Serum levels of interleukin-6 and interleukin-10 as biomarkers for Hepatocellular carcinoma in Egyptian patients. ISRN Hepatol 2013; 2013: 412317.

[33] Hsia CY, Huo TI, Chiang SY, Lu MF, Sun $\mathrm{CL}$, $\mathrm{Wu} \mathrm{JC}$, et al. Evaluation of interleukin-6, interleukin-10, and human hepatocyte growth factor as tumor markers for hepatocellular carcinoma. Eur J Surg Oncol 2007; 33(2):208-12.
[34] Stetson DB, Medzhitov R. Type I interferons in host defense. Immunity 2006; 25(3):373-81.

[35] Riordan SM, Skinner N, Nagree A, McCallum $\mathrm{H}$, McIver CJ, et al. Peripheral blood mononuclear cell expression of toll-like receptors and relation to cytokine levels in cirrhosis. Hepatology 2003; 37 : 1154-64.

[36] Tarrats N, Moles A, Morales A, Garcia-Ruiz C, Fernandez-Checa JC, Marí M. Critical role of tumor necrosis factor receptor 1 , but not 2 , in hepatic stellate cell proliferation, extracellular matrix remodeling, and liver fibrogenesis. Hepatology 2011; 54(1): 319-27.

[37] Grunhage F, Rezori B, Neef M, Lammert F, Sauerbruch T, Spengler U, Reichel C.. Elevated soluble tumor necrosis factor receptor 75 concentrations identify patients with liver cirrhosis at risk of death. Clin Gastroenterol Hepatol 2008; 6(11): 1255-62.

[38] Zekri AR, Youssef AS, Bakr YM, Gabr RM, Ahmed OS, Elberry MH, Mayla AM, Abouelhoda M, Bahnassy AA. Early detection of hepatocellular carcinoma co-occurring with hepatitis $\mathrm{C}$ virus infection: A mathematical model. World J Gastroenterol 2016; 22(16):4168-82.

[39] Zekri AR, El Deeb S, Bahnassy AA, Badr AM, Abdellateif MS, Esmat G, Salama H, Mohanad M, ElDien AE, Rabah S, Abd Elkader A. Role of relevant immune-modulators and cytokines in hepatocellular carcinoma and premalignant hepatic lesions. World J Gastroenterol 2018; 24(11):1228-38. 